\title{
Influence of abiotic factors on mass capturing of lepidopterous moths by sex pheromone traps
}

Saghir Ahmad ${ }^{1}$, Ali Raza ${ }^{1}$, Muhammad Akram ${ }^{1}$, Muhammad Aslam², Wajad Nazir ${ }^{1}$, Abdul Latif Khan Tipu ${ }^{1}$, Muhammad Shahid ${ }^{1 *}$, Abdul Karim $^{1}$, Muhammad Rafiq ${ }^{1}$, Muhammad Shakeel ${ }^{3}$ and Muhammad Rafiq Shahid $^{1 *}$

1. Cotton Research Institute, Multan-Pakistan

2. Soil and water testing Laboratory, Multan-Pakistan

3 South China Agriculture University-China

*Corresponding author's email: shahid1364@yahoo.com

Citation

Saghir Ahmad, Ali Raza, Muhammad Akram, Muhammad Aslam, Wajad Nazir, Abdul Latif Khan Tipu, Abdul Karim, Muhammad Rafiq, Muhammad Shakeel, and Muhammad Rafiq Shahid. Influence of abiotic factors on mass capturing of lepidopterous moths by sex pheromone traps. Pure and Applied Biology. Vol. 9, Issue 4, pp2609-2616. http://dx.doi.org/10.19045/bspab.2020.90277

\begin{tabular}{llll}
\hline \hline Received: 01/04/2020 & Revised: 01/06/2020 & Accepted: 12/06/2020 & Online First: 29/06/2020 \\
\hline
\end{tabular}

\section{Abstract}

The increasing trend of insecticide resulted in insecticide resistance; resultantly alternate options are requisite to manage insect pests. Pheromone traps are used to capture the flying insects of the opposite sex. They are used to monitor the presence of lepidopterans moths in a specific locality. Present studies were carried out to assess the population abundance of lepidopterans moths of cotton. For this purpose, specific lures of each lepidopterans moth were installed all around the cotton field at the height of 5 feet. Based on the results of the present studies, it was found that pink bollworm was more abundant amongst all the other moths of cotton. It was the most damaging insect pest of cotton. Its peak trapping was recorded during the months of September when day and night temperature reaches to 35 and $25{ }^{\circ} \mathrm{C}$ respectively. From the results, it was found that pheromone traps are a very useful source of monitoring lepidopterans moths. It was concluded that the efficiency of pheromone traps was high at limits of $30-35{ }^{\circ} \mathrm{C}$ day and $20-25{ }^{\circ} \mathrm{C}$ night temperature.

Keywords: Abiotic factor; American bollworm; Lepidopterans moths; Pheromone trap; Pink bollworm; Spotted bollworm

\section{Introduction}

Pheromones are basically a scent produced by the female insect to attract their male counterpart for mating [1]. Therefore, pheromone traps are designed as sex lure used as an important sampling tool for monitoring and mass trapping of flying insects [2]. Pheromone traps are usually installed in or around the vicinity of the cropping area of the fields. Most commonly, they are used to find out the presence and seasonal activity of insect pest species; however, at higher doses, they are also used for management purposes [3-5]. Based on the 
collected information from pheromone traps over a more extended period of time can be used to devise prediction models well before the onset of incidence and ways to adopt integrated pest management strategies precisely and accurately against seasonal pests $[3,4]$.

Cotton crop is affected by both sucking and chewing insect pests that cause huge crop losses. Pink bollworm (Pectinophora gossypiella), army worm (Spodoptera litura), American bollworm (Helicoverpa armigera) and spotted bollworm (Earias insulana \& E. vittella) chewing insects belong to order Lepidoptera and their adults are called as moth. Pheromone traps have been reported to be useful for monitoring and management of these moths [5]. Young ones of these insect pest species are called caterpillar. The caterpillar of armyworm attack on vegetative parts while all the others discussed moth caterpillars are voracious feeders and damage the reproductive parts like flowers, buds and bolls of cotton. Farmers mostly rely on the use of insecticides for the management of these insect pest species. The use of insecticide is harmful and less effective as compared to pheromone technique mainly due to environmental pollution and healthhazardous problem during application, mammalian toxicity and residual effects on beneficial fauna and increase in insecticide resistance problem [6]. Pheromone trap is a unique natural foolproof technique which has minimum to no adverse effect on the environment and non-targeted fauna [7]. Before mating disruption technique, farmers had to depend on chemical sprays for management of lepidopterans moths and resulted in an imbalance of natural ecosystem between natural enemies and insect pests [3]. Mating disruption does not completely stop, but delay in females mating, reduced fecundity $[8,9]$ and their ability to select suitable sites for oviposition. Harmonization about herbivore pest and crop stage also play an important role for the effective management of lepidopterans moths by using pheromone traps $[4,10]$, because insects living in an environment with many volatile compounds interact with each other and finally modify the behavior and the physiology of insect pest species [11]. Environmental factors include all abiotic parameters especially maximum and minimum temperature greatly influence the effectiveness of trap due to its effect on the evaporation of chemical confined in the capsule. Keeping in view the need of pheromone traps to monitor the presence of moths, traps were installed in the research area of the Cotton Research Institute, Multan during 2017. The data of moth catches and abiotic factor recorded were subjected to correlation studies.

\section{Materials and methods}

The current studies were carried out at the research area of Cotton Research Institute Multan, Punjab (Pakistan), located at an altitude of 133 meters above the sea level and latitude of $\left(30.15^{\circ} \mathrm{N}\right)$ and longitude of $\left(71.52^{\circ}\right.$ E). Commercially available sex pheromones of lepidopterans moths (PBW, ABW, SBW and Armyworm) were installed for the monitoring of lepidopterans moths during the year 2017 and 2018. The pheromones containing rubber capsule (Septa) or lures (suspended in the center of the trap) were used for the monitoring of adult moth emergence. These pheromones traps were placed in the center and outer sector on stone/iron slabs at the level of crop canopy. The data regarding overwintering moth emergence and during the cotton season were made and recorded on a daily basis during 2017-18. Then observations on moth catch, weekly mean maximum, minimum temperature and percent relative humidity were taken into the record on a weekly basis.

\section{Statistical analysis}

The data regarding population dynamics of lepidopterans moth catches (PBW, ABW, 
SBW and Army worm) in the pheromone traps, mean maximum and minimum temperature, percent relative humidity was subjected to correlation Pearson and linear multiple regression analysis by using statistical software Minitab 17 package. The coefficient of determination $\left(\mathrm{R}^{2}\right)$ was also determined through multiple regression models.

\section{Results and discussion}

Semiochemicals are chemical, or it's a compound mixture that is source of communication. They are divided into two classes, i.e., intraspecific and interspecific signals. Pheromones are intraspecific signals that aid in finding the mate [11]. The oneday-old female emits pheromone at a certain time and male moths synchronize their activity by flying to locate the source for mating with female. This flight is termed as attraction [8]. Pheromone trap is a useful source of indication about the presence of insect pests in a specific locality [12]. Insects respond with respect to pheromone to find out its counterpart, or food hosts [8]. The technique is most important because the attract and kill technique is very useful from the pest management point of view for monitoring and mass-trapping of bollworms [7].

In present studies, abiotic factors (especially temperature, relative humidity and wind speed) highly influence the effectiveness of pheromone traps. From the results of present studies, it was found that both maximum and the minimum temperature had a negative effect on moth catches of all Pink, spotted and American bollworm. It might be due to the effect of temperature on the activity of these insect pest species or due to its effect on the composition of chemical being used as a lure in pheromone traps. At lower temperatures, insects undergo dormant stages and at high temperatures, there is maximum chance of mortality. Accuracy of moth catches in sex traps depends upon the abiotic factor as well as the interaction between insect activity and trap performance [13]. Soil temperature affects the emergence of moths from underground pupae. Crop stage also plays an important role that serves as a substrate for egg-laying, feeding and shelter for the newly hatched larvae of lepidopterans moths. However, the installation canopy level of crop affected the efficacy of pheromone traps for moth catches of lepidopterans moths.

In the present studies, the average maximum temperature during the crop season (when traps were used) was 32.29 that ranged from 18.49 to $41.59{ }^{\circ} \mathrm{C}$ and 20.8 was an average minimum temperature that ranged from 7.13 to $36.58{ }^{\circ} \mathrm{C}$ respectively. The average relative humidity was 71.11 that ranged from 41.99 to $90.0 \%$. During crop season 4.09 was average moth catches/trap of pink bollworm that ranged from 0.0 to 17.22 numbers, whereas the average was 0.27 ranging from 0.0 to 2.40 respectively for American bollworm. Similarly, on average spotted bollworm was 0.93 that ranged from 0.015 to 5.43 maximum and minimum, respectively and the Average number of armyworm was 0.28 that ranged from 0.0 to 1.15 number/trap respectively (Table 1 ).

\section{Association between abiotic factors and moth catches}

Maximum and minimum temperature had a negative but non-significant correlation with moth catches of pink bollworm, spotted and american bollworm. A positive correlation was found between armyworm with minimum and maximum temperature. , The negative association, existed between relative humidity with american and armyworm but a positive association with pink bollworm and spotted bollworm, respectively (Table 2). 
Table 1. Descriptive statistics regarding Lepidopteran's moth catches and abiotic factors

\begin{tabular}{|c|c|c|c|c|c|c|}
\hline & N & Mean & SD & Sum & Min. & Max. \\
\hline Max. Temp. & 12 & 32.2 & 7.92 & 386.75 & 18.49 & 41.59 \\
\hline Min. Temp. & 12 & 20.80 & 9.88 & 249.65 & 7.13 & 36.58 \\
\hline R.H. \% & 12 & 71.1 & 14.72 & 853.4 & 41.99 & 90.01 \\
\hline Pink BW. & 12 & 4.09 & 6.32 & 49.11 & 0 & 17.22 \\
\hline American BW. & 12 & 0.27 & 0.68 & 3.25 & 0 & 2.40 \\
\hline Spotted BW. & 12 & 0.93 & 1.74 & 11.18 & 0.015 & 5.43 \\
\hline Army Worm & 12 & 0.28 & 0.34 & 3.38 & 0 & 1.15 \\
\hline
\end{tabular}

$\mathrm{N}=$ Number of observations, $\mathrm{SD}=$ Standard deviation, Min. $=$ Minimum temperature, Max.= Maximum temperature, R.H.= Relative humidity, BW= Bollworm

Table 2. Pearson Correlation between abiotic factors and lepidopterans moth catches

\begin{tabular}{|c|c|c|c|c|c|c|c|}
\hline \multirow[t]{2}{*}{ Variable } & \multicolumn{2}{|c|}{$\begin{array}{c}\text { Temperature } \\
\text { (Celsius) }\end{array}$} & \multirow[t]{2}{*}{ R.H. \% } & \multicolumn{3}{|c|}{ Bollworms } & \multirow{2}{*}{$\begin{array}{l}\text { Army } \\
\text { Worm }\end{array}$} \\
\hline & Max. & Min. & & Pink & American & Spotted & \\
\hline Max. & 1 & & & & & & \\
\hline Min. & 0.91 & 1 & & & & & \\
\hline R.H. \% & -0.901 & -0.739 & 1 & & & & \\
\hline Pink BW & -0.0096 & -0.061 & 0.147 & 1 & & & \\
\hline American BW & -0.087 & -0.145 & -0.020 & -0.008 & 1 & & \\
\hline Spotted BW & -0.096 & -0.165 & 0.250 & 0.913 & -0.119 & 1 & \\
\hline Army Worm & 0.288 & 0.158 & -0.162 & 0.882 & -0.066 & 0.706 & 1 \\
\hline
\end{tabular}

Min.= Minimum temperature, Max.= Maximum temperature, R.H.= Relative humidity, BW= Bollworm

Proportion of moth catches during different months

Graphical representation revealed that the proportion of moths/ trap indicated that among the relative proportion of moth catches, the maximum was of pink bollworm during all the months under observation. Likewise, spotted bollworm moth catches were more during the month of July, whereas American bollworm during March., The minimum proportion of army worm, was recorded in traps (Fig. 1a). Graphical representation exhibited that the population of moth catches was observed during the months of February, March and April, again during the months of July, August, September, October and November (Fig. 1b).
Effect of abiotic factors on pink bollworm moth catches per trap

Graphical presentation exhibited that pink bollworm moths per trap increased gradually during March when temperature exceed from $25^{\circ} \mathrm{C}$ and $12{ }^{\circ} \mathrm{C}$ for maximum and minimum temperature. Peak moth catches were recorded when maximum temperature was 35 and minimum was 25 during April. It declined later on when day temperature/maximum temperature exceeded from $35{ }^{\circ} \mathrm{C}$. Next peak moth catches were recorded during the month of October when maximum temperature was 35 and minimum temperature was again at $25^{\circ} \mathrm{C}$. The graph further exhibited that Relative humidity during both peak periods was $66-72 \%$ (Fig. 2). 

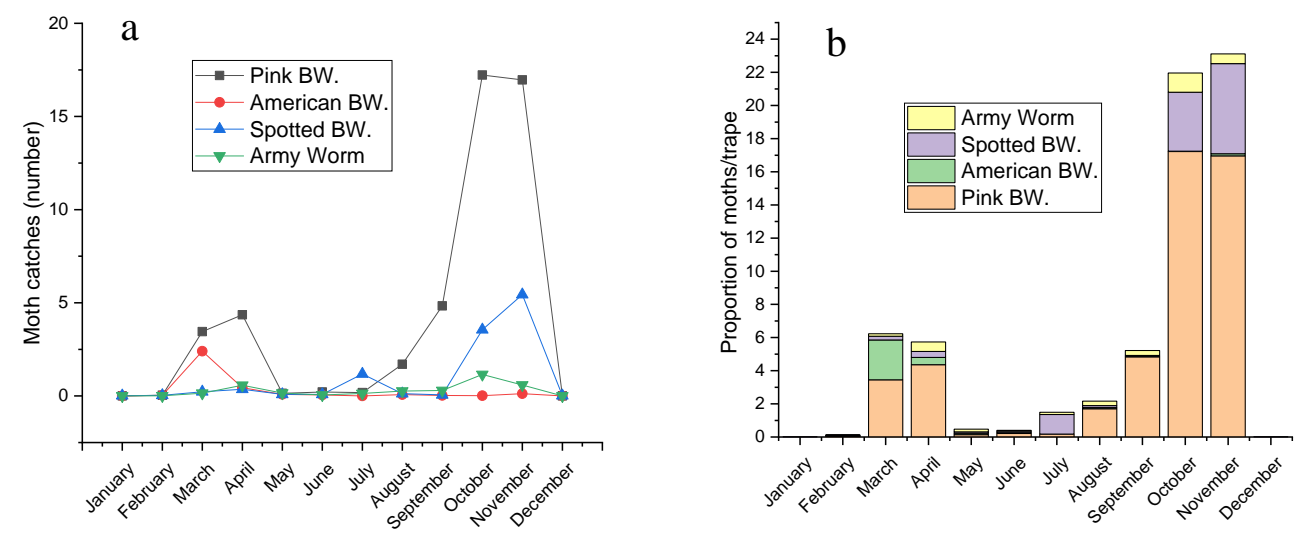

Figure 1. Graphical representation regarding (a) moth catches per trap\& (b) their proportion during different months of the year

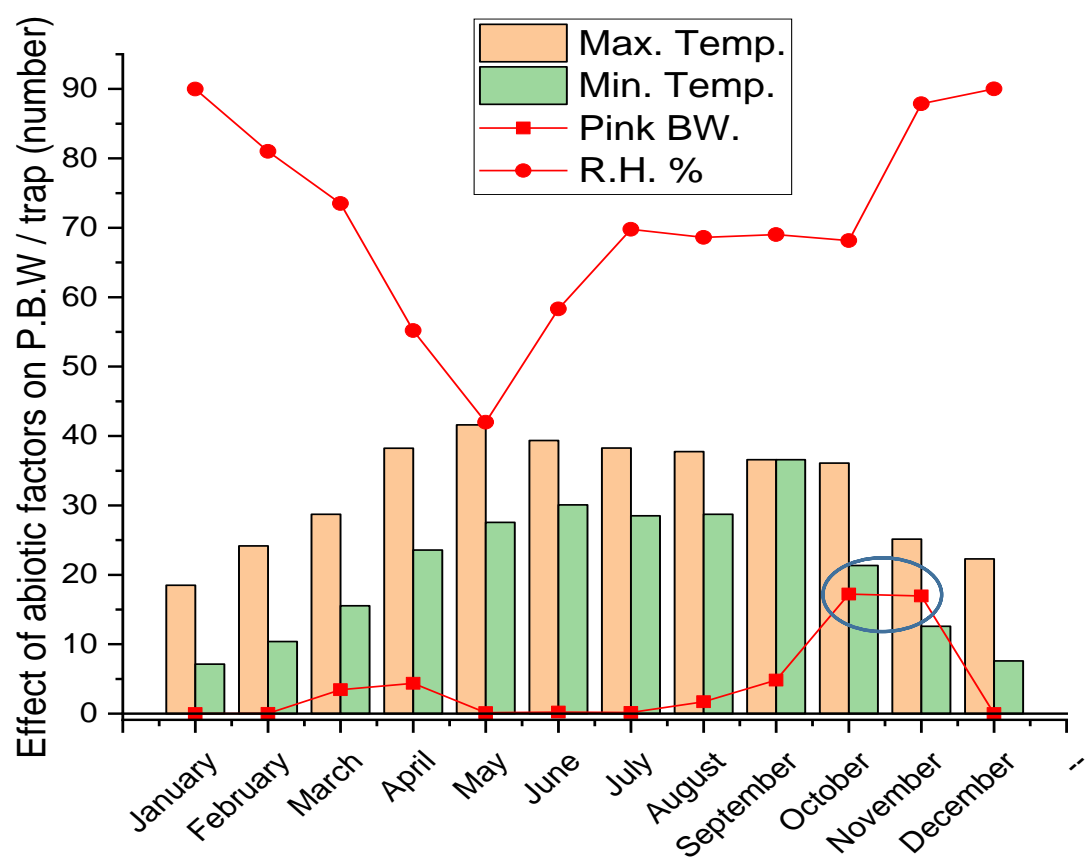

Figure 2. Effect of abiotic factors on pink bollworm moth catches per trap

Effect of abiotic factors on American bollworm moth catches per trap

Graphical presentation exhibited that American bollworm moths per trap remained negligible throughout the cotton growing season and very minute increase in moth catches per trap was observed during March (Fig. 3).

Effect of abiotic factors on spotted bollworm moth catches per trap

Graphical presentation exhibited that spotted bollworm moths per trap remained negligible 
throughout the season except during October and November (Fig. 4).

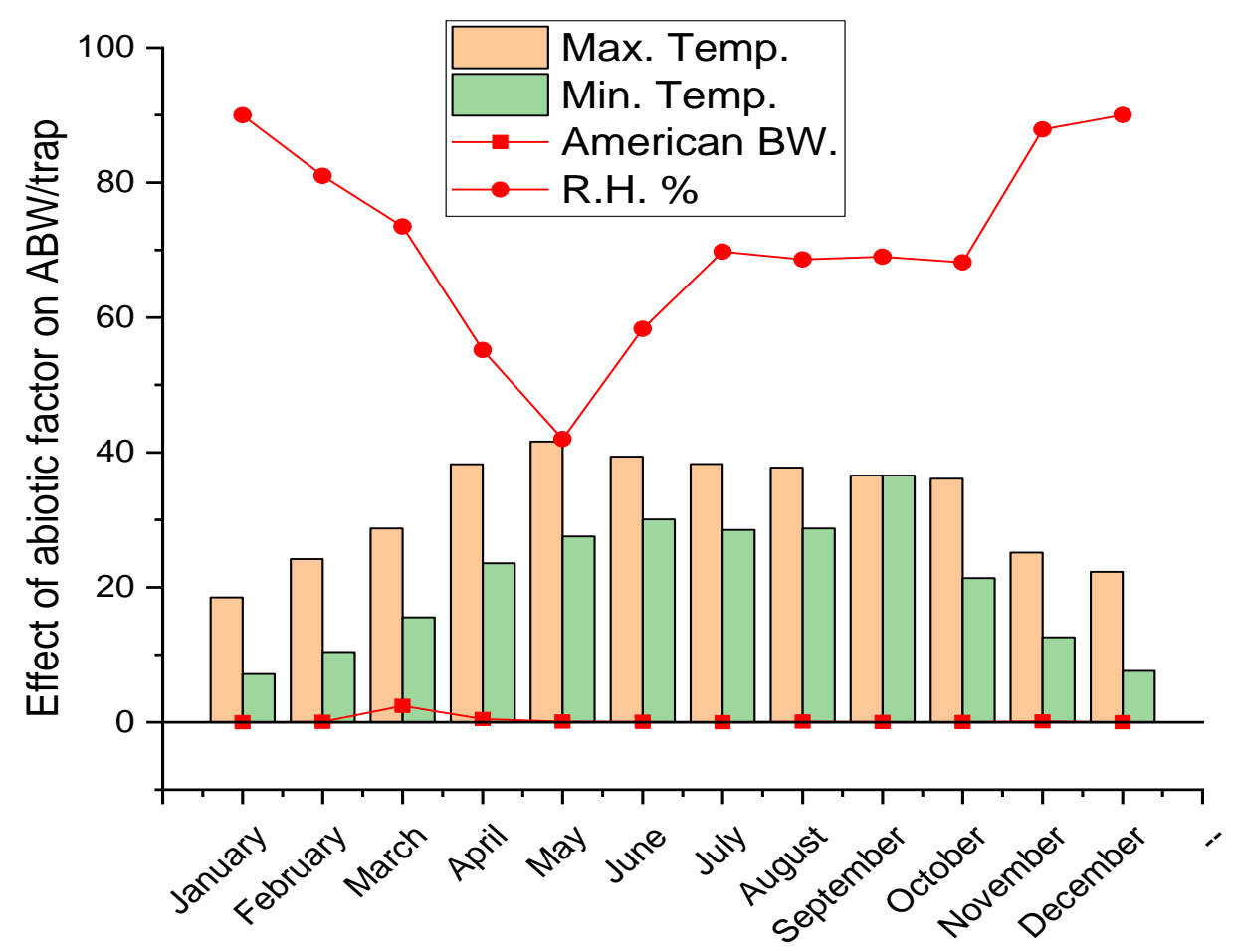

Figure 3. Effect of abiotic factors on American bollworm moth catches per trap

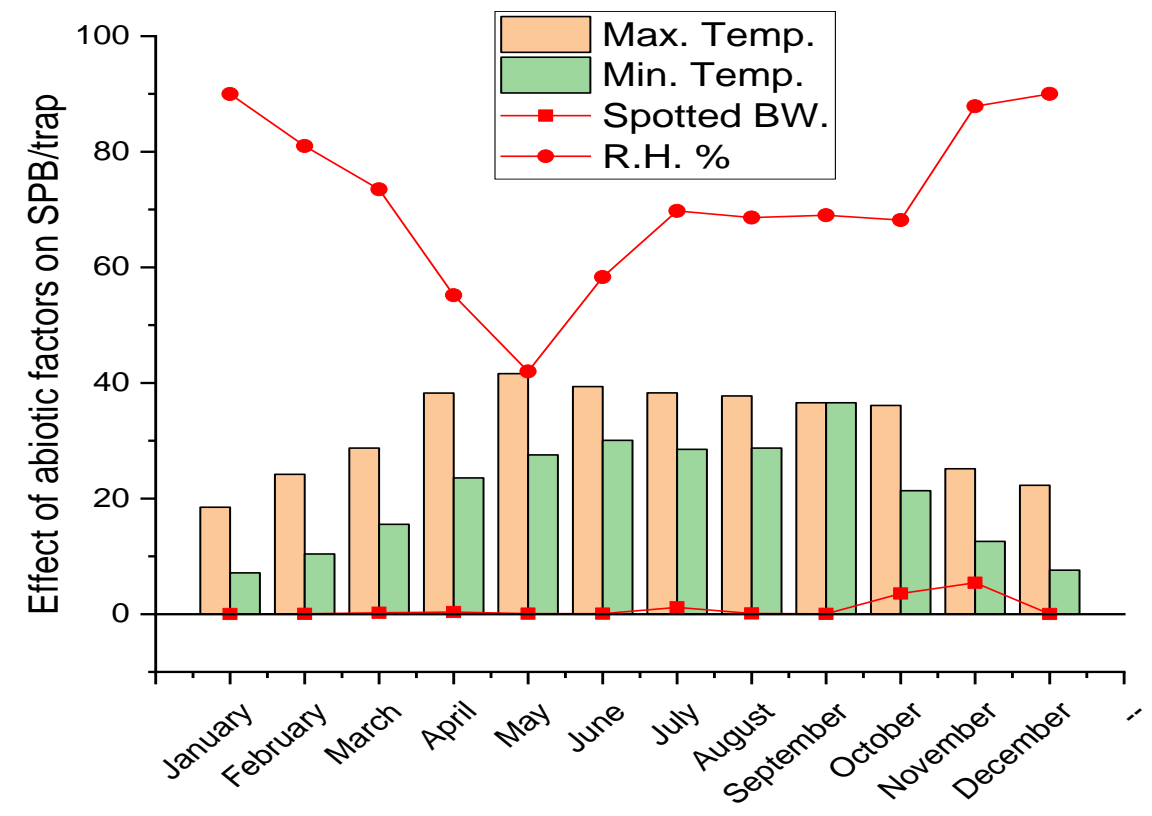

Figure 4. Effect of abiotic factors on American bollworm moth catches per trap 
Effect of abiotic factors on armyworm moth catches per trap

Graphical presentation exhibited that Armyworm moths per trap remained negligible throughout the cotton growing season (Fig. 5).

At optimum temperature and humidity range there are maximum survival chances of insects. From the results, it was found that peak moth catches were recorded during the month of October when maximum temperature was 35 and minimum temperature was again at $25{ }^{\circ} \mathrm{C}$, whereas relative humidity during both peak periods was $66-72 \%$. According to Singh \& Sachan [14] other than temperature, relative humidity maintains viability, dispensability and durability of the trap.

The accuracy of moth catch data depends upon the abiotic factor as well as the interaction between insect activity and trap performance, as reported by [13]. According to Sinha and Jain [2], other than temperature, relative humidity maintains viability, dispensability and durability of the trap. However, synchronization between pest and crop growth is important for effective management of moths with the help of pheromone traps $[4,10]$. Therefore, pheromone traps are used to overcome all discussed challenges.

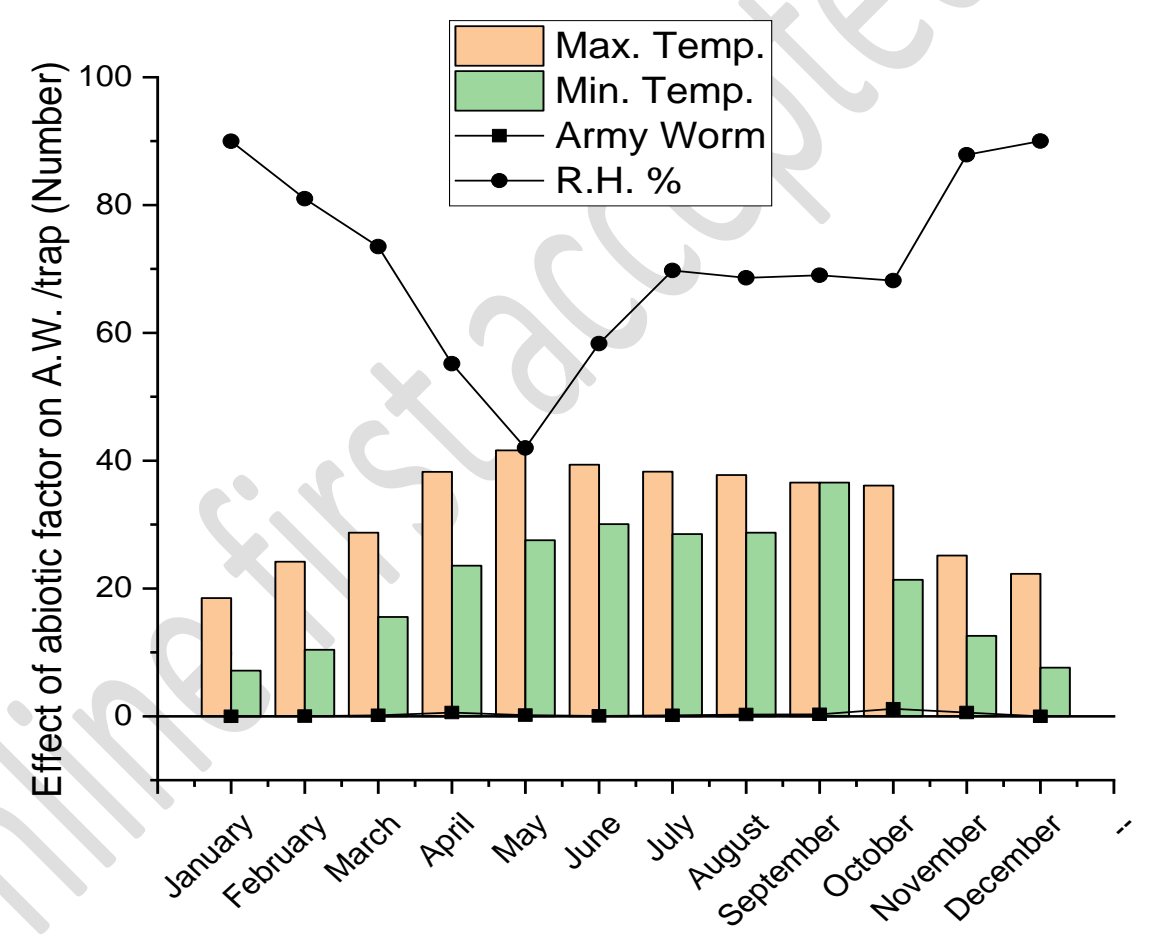

Figure 5. Effect of abiotic factors on american bollworm moth catches per trap

\section{Conclusion}

The proportion of pink bollworm moth catches was more than American, army and spotted bollworm of cotton and peak trapping was recorded during the months of September when day and night temperature reaches to 35 and $25{ }^{\circ} \mathrm{C}$ respectively. From the results it was concluded that pheromone traps are very useful source of monitoring and their management well in time.

Authors' contributions

Conceived and designed the experiments: A Raza, M Akram, MR Shahid \& S Ahmad, Performed the experiments: A Raza, M 
Akram, MR Shahid \& S Ahmad, Analyzed the data: M Shahid, Contributed materials/ analysis/ tools: M Aslam, A Karim, M Rafiq \& M Shakeel, Wrote the paper: MR Shahid, W Nazir \& ALK Tipu.

\section{References}

1. Baker TC (2008). Use of pheromones in IPM. In (Editors): Radcliffe, $\mathrm{T}$ and Hutchinson, B. Integrated pest management, Cambridge Uni Press 271-285.

2. Sinha SN \& Jain DK (1992). Field studies on pheromone trap catches of Helicoverpa armigera monitoring seasonal abundance and larval infestation on chickpea and the effect of climate on trap catches. Indian J Plant Prot 20: 149-157.

3. Shahid MR, Suhail A, Arif MJ, Gogi MD, Shahzad MA \& Hussain S (2007). Effectiveness of Trichogramma chilonis (Hymenoptera: Trichogrammatidae) against sugarcane stem borer (Chilo infuscatellus Snellen) (Lepidotera: Pyrallidae). Pak Entomol 29(2): 141146.

4. Patil BV, Nandihalli BS, Hugar P \& Somashekar (1992). Influence of weather parameters on pheromone trap catches of cotton bollworms. Karnataka J Agri Sci 5: 346-350.

5. Prasannakumar NR, Chakravarthy AK \& Naveen AH (2012). Influence of weather parameters on pheromone trap catches of potato cutworm, Spodoptera litura (Fabricius) (Lepidoptera: Noctuidae). Curr Biotica 5(4): 508-512.

6. Jaffé K, Sánchez P, Cerda H, Hernández JV, Jaffé R, Urdaneta N, Guerra G, Martínez R \& Miras R (1993). Chemical ecology of the palm weevil Rhynchophorus palmarum (L.) (Coleoptera: Curculionidae): attraction to host plants and to male-produced aggregation pheromone. J Chem Ecol 19: 1703-1720.

7. El-Sayed AM (2015). The pherobase: database of insect pheromones and semiochemicals, 2008 . http://www.pherobase.com.

8. Yildiz S, Gezer ED \& Yildiz UC (2006). Mechanical and chemical behavior of spruce wood modified by heat. Building and Environ 41(12): 1762-1766.

9. Baker TC (2008). Use of pheromones in IPM. In (Editors): Radcliffe, $\mathrm{T}$ and Hutchinson, B. Integrated pest management, Cambridge Uni Press 271-285.

10. Nakache J, Dunkelblum E, Kehat M, Anshelevich \& Mirian H (1992). Mating disruption of the spiny bollworm, Earias insulana, with Shin Etsu twist-tie ropes in Israel. Bull Entomol Res 82: 369-373.

11. Reddy GVP \& Guerrero A (2004). Interactions of insect pheromones and plant semiochemicals. Trends Plant Sci 9: 253-261.

12. Larsson MC (2016). Pheromones and other semiochemicals for monitoring rare and endangered species. J Chem Ecol 42(9): 853-868.

13. Otuka A, Matsumura M \& Tokuda M, (2020). Dispersal of the Common Cutworm, Spodoptera litura, Monitored by Searchlight Trap and Relationship with Occurrence of Soybean Leaf Damage. Insects 11(7): 427.

14. Singh KN \& Sachan GC (1991). Assessment of the use of sex pheromone traps in the management of Spodoptera litura. Indian J Proc 21(1): 7-13. 